In the March issue, Vol. 16, No. 3, the printer inadvertently ran in authors' names, removing the spaces between the first and last names and deleting the "and" between the author's names. The printer sincerely apologizes for the error. On page 307, the authors should have been printed as below:

\title{
Trap for MAbs: Characterization of Intact Monoclonal Antibodies Using Reversed-Phase HPLC On-Line with Ion-Trap Mass Spectrometry
}

\author{
John C. Le and Pavel V. Bondarenko \\ Department of Pharmaceutics and Drug Delivery, Amgen Inc., Thousand Oaks, California, USA
}

For the first time, the characterization of intact 150-kDa monoclonal antibodies (MAbs) using a commercially available three-dimensional ion-trap mass spectrometer (IT-MS) is reported. The IT-MS analysis was performed on-line with reversed-phase high performance liquid chromatography (RP-HPLC) on a POROS column using a nontraditional solvent system of acetonitrile, isopropanol, ethanol, and water in formic acid. The operating parameters of the IT-MS were optimized by extending the mass range to $\mathrm{m} / \mathrm{z} 4000$ and elevating the tube lens offset voltage value to around $-100 \mathrm{~V}$. Mass accuracy better than $300 \mathrm{ppm}( \pm 40 \mathrm{Da})$ has been routinely achieved for these macromolecules. Multiple peaks $162 \mathrm{Da}$ apart due to the hexose variants of the monoclonal IgG antibodies were partially resolved in mass spectra. Several commercial and chimeric antibodies have been investigated in this study. (J Am Soc Mass Spectrom 2005, 16, 307-311) (C 2004 American Society for Mass Spectrometry 